\title{
Frequency of functional drug disposition gene polymorphism in Thai population: relevance to antiretroviral drugs
}

\author{
A Chaikan*1, N Chierakul ${ }^{2}$, N Saguenwong ${ }^{3}$, C Chuchuttaworn ${ }^{4}$, A Owen ${ }^{1}$, \\ L Dickinson $^{1}$, SH Khoo ${ }^{1}$, DJ Back ${ }^{1}$ and GR Davies ${ }^{1}$
}

\author{
Address: ${ }^{1}$ Department of Pharmacology and Therapeutics, University of Liverpool, Liverpool, UK, ${ }^{2}$ Siriraj Hospital, Bangkok, Thailand, \\ ${ }^{3}$ Bamrasnaradura Infectious Diseases Institute, Nonthaburi, Thailand and ${ }^{4}$ Central Chest Hospital, Nonthaburi, Thailand \\ * Corresponding author
}

from Ninth International Congress on Drug Therapy in HIV Infection

Glasgow, UK. 9-13 November 2008

Published: 10 November 2008

Journal of the International AIDS Society 2008, I I (SuppI I):P237 doi:I0.I I86/I758-2652-I I-SI-P237

This abstract is available from: http://www.jiasociety.org/content/I I/SI/P237

(c) 2008 Chaikan et al; licensee BioMed Central Ltd.

\section{Purpose of the study}

Significantly higher plasma exposure of some protease inhibitors (PIs) has been observed in Thai subjects compared to Caucasians. These differences may partially be explained by factors such as body weight and diet. However, pharmacogenetic differences may also contribute. The aim of this study was to investigate, in a Thai population, the frequency of functional polymorphisms in genes known to influence plasma concentrations of antiretroviral drugs.

\section{Methods}

Eighty-four Thai subjects were included in this study. Genotyping for CYP2B6 (516G>T and 983T>C), CYP3A4 ($392 \mathrm{~A}>\mathrm{G})$, CYP3A5 $(6986 \mathrm{~A}>\mathrm{G}), \quad A B C B 1 \quad(1236 \mathrm{C}>\mathrm{T}$, $3435 \mathrm{C}>\mathrm{T}$ and $2677 \mathrm{G}>\mathrm{T}), A B C C 1 \quad(-260 \mathrm{G}>\mathrm{C}), A B C G 2$ (421C $>\mathrm{A})$, SLCO1B1 (521T $>\mathrm{C})$ and $P X R(63396 \mathrm{C}>\mathrm{T}$ and $44477 \mathrm{~T}>\mathrm{C}$ ) was conducted by real-time PCR based allelic discrimination. Hardy-Weinberg equilibrium was assessed by $\chi^{2}$ test of observed versus predicted genotype frequencies. Fisher's exact test was used to determine differences in allele frequency between Thai and previously reported Caucasian populations.

\section{Summary of results}

All genotype frequencies were in the Hardy-Weinberg equilibrium. The minor allele frequency for $516 \mathrm{G}>\mathrm{T}$, $983 \mathrm{~T}>\mathrm{C},-392 \mathrm{~A}>\mathrm{G}, 3435 \mathrm{C}>\mathrm{T}, 2677 \mathrm{G}>\mathrm{T},-260 \mathrm{G}>\mathrm{C}$ and $521 \mathrm{~T}>\mathrm{C}$ was $0.35,0,0.02,0.45,0.45,0.03$ and 0.12 , respectively and not significantly different from Caucasians. The $\mathrm{G}$ allele frequency for CYP3A5 6986A>G was lower in Thai $(0.65)$ than in Caucasians $(0.92 ; \mathrm{p}<$ $0.0001)$. Similarly, the minor allele frequencies for ABCB1 1236C >T and ABCG2 421C>A were significantly higher in Thai compared to Caucasian populations $(0.65$ vs. $0.46, \mathrm{p}=0.002$ and 0.24 vs. $0.10, \mathrm{p}=0.003$, respectively). Finally, PXR SNPs were both at different frequency in Thai vs. Caucasian populations $(0.34$ vs. $0.40, \mathrm{p}=$ 0.006 for $63396 \mathrm{C}$ and 0.45 vs. $0.16, \mathrm{p}<0.0001$ for 44477 $\mathrm{T})$.

\section{Conclusion}

Although the different allele frequencies for $\mathrm{ABCB} 1$ and ABCG2 could have a modest impact on the bioavailability, the over-representation of CYP3A5 $6986 \mathrm{G}$ would be expected to result in lower drug concentrations of PIs. However, we have previously shown an association of PXR SNPs with atazanavir plasma concentrations and so genotype-phenotype studies for these SNPs in Thai populations are now warranted. 